\title{
Dextran-containing nanocarriers significantly promote greater anchorage dependent cell growth and density compared to microcarriers
}

\author{
Edmund Anton ${ }^{1,2}$, Kambalapally Swetha ${ }^{1,2}$ Wilson Thomas ${ }^{2}$, and R J Nicolosi ${ }^{2}$ \\ ${ }^{1}$ Biomedical Engineering and Biotechnology PhD Program \\ ${ }^{2}$ Centers for Health and Disease Research, Division of Nanomedicine, University of Massachusetts Lowell 3 Solomont way, Lowell, MA 01854 \\ * Corresponding author:aedmund@hotmail.com (Edmund Anton)
}

\begin{abstract}
Microcarriers containing cellulose-derived materials have been successfully applied to enhance the growth of anchorage-dependent cells maintained especially in bioreactors. By replacing microcarriers with nanocarriers containing dextran, we hypothesized that the density of the anchoragedependent cells would rise dramatically because the decreased particle size and associated enhancement in surface to volume ratios of nanoparticles contained within the nanoemulsion-based nanocarriers would increase the number of dextran molecules for the anchorage-dependent cells to attach to. Our studies utilized self-assembly nanoemulsions (SANE) formed by a modified phase inversion temperature (PIT) process to produce dextran oil and surfactant-containing nanocarriers having mean particle sizes of $26 \mathrm{~nm}$ compared to microcarriers which were greater than $6000 \mathrm{~nm}$. Our results demonstrated that dextran-containing nanocarriers allowed up to 10 fold greater cell density, $12 \%$ more media lactate concentration, $83 \%$ higher cell lysate protein and 59\% greater glucose concentration, used as a measure of polymer levels in the nanocarriers compared to microcarriers. In conclusion, nanocarriers with increased numbers of dextran molecules, developed in these studies may be useful to further increase the production of anchorage-dependent animal cell-derived products or production of mass cell growth for other applications.
\end{abstract}

Keywords: Nanocarriers, Nanoemulsions, Nanoparticles, Microcarriers, Cell culture, CHO

Citation: E. Anton, et al. Dextran-containing nanocarriers significantly promote greater anchorage dependent cell growth and density compared to microcarriers. Nano Biomed. Eng. 2012, 4(1), 29-34.DOI: 10.5101/nbe.v4i1.p29-34.

\section{Introduction}

The utilization of mass cultures of animal cell lines is fundamental to the manufacture of enzymes and many products of biotechnology (1). The biologics produced by recombinant DNA (rDNA) technology in animal cell cultures include, but are not limited to proteins such as enzymes, synthetic hormones, immuno-biologicals, and anticancer agents. Although many simpler proteins can be produced using rDNA technology in bacterial cultures, more complex proteins that are glycosylated or carbohydrate-modified, currently must be produced by anchorage-dependent animal cells. They are usually manufactured in bioreactor systems that require cell adhering surfaces such as tissue culture plastic [1].

Microcarrier technology has been applied to anchorage-dependent cells for the production of a variety of biologic products since these microcarriers have the advantage of [a] increasing production capacity [b] enhancing separation of cells from secreted end products [c] protecting against physical stress [d] reducing the required volume of cell culture media [e] reducing labor intensity and [f] lowering risk of contamination [2]. Moreover, the bioreactor operation requirements are virtually identical to those for typical suspension cultures in fermentors except that the upper limit for agitation is lower for mixing nutrients without disturbing the cells.

Operating modes such as batch, fed-batch, and perfusions are routinely used in microcarrier systems. Microcarrier technology, developed over the past three decades still remains the cornerstone for cell culture production of biologics due to its versatility in supporting the growth of a variety of anchorage-dependent cells and therefore will continue to insure its unique place in bioprocessing [3]. However, that having been said, there are opportunities to improve the efficiency of anchorage- 
dependent cell production of biologics such as, but not limited to the utilization of nanosphere-containing carrier systems.

In porous cellulose that characterizes the cellulosebased and microcarrier-dependent cell culture systems, cells adhere on the surface and are entrapped in the pores (100-200 $\mu \mathrm{M}$ in diameter) of the cellulose of the spherical microcarriers and are cultured in stirred suspension bioreactors [3]. However, shear stress exerted on the surface of the microcarriers has been reported to damage cells and/or decrease their viability in vigorously stirred suspension bioreactors [4]. In cell aggregate cultures, anchorage-dependent cells form spherical aggregates and grow in suspensions [5] and although cells within aggregates could be protected from the shear stress in stirred suspension bioreactors, not all types of cells are induced to form cell aggregates and, moreover, aggregate formation rate is slow [6].

Taken together, these disadvantages in current cell culture systems for the production of biologics suggest a need for a more efficient technology such as, but not necessarily limited to the use of dextran-containing nanocarriers in combination with anchorage-dependent cells.

Additionally, it is well established that during the initial phase purification of the harvested biologic from the production bioreactor, capture purification is the first critical step of protein purification. Speed and capacity are the primary objects of this step [7] and despite more recently-developed microcarrier systems being formulated with lower clogging effect, varying degrees of clogging still occurs during this filtration process which can cause unwanted production delay, labor and product lost [8]. By virtue of their smaller particle size, the proposed use of nanocarriers will pass through the filtration process during the capture phase [8], which can be subsequently filtered out later using commercially-available nano filters.

Earlier preparations of microcarriers were composed of dextran because it had been previously shown that the addition of the glucose polymer Dextran to the microcarrier lowered charge density and led to improvement of microcarrier technology [9], for example, dextran-derived materials have been widely used in biologics application because they [a] provide a matrix for anchorage-dependent cells to attach to [b] have a simple glucose backbone raising the possibility that functional groups can be attached for targeting purposes [c] have a neutral $\mathrm{pH}$ [d] are water soluble [e] are biodegradable, [f] demonstrate ease of removal by simple filtration and $[\mathrm{g}]$ are biocompatible [10]. Thus, dextran was also included in our nanocarrier system. More recently, microcarriers are being prepared with a very porous cellulose polymer [11] which presumably enhances the entrapment of cells adhering to the microcarrier.

Self-assembling nanoemulsions (SANE) using phase inversion temperature (PIT) technology (patent pending) was the system used to prepare the nanosphere-containing dextran nanocarriers in this communication. These nanoemulsions contained nanocarriers in an oil-watersurfactant interphase having very small particle sizes (@ 25nm). This preparation was modified to include the polymer dextran as a potential mechanism(s) for increased adherence of cells to the nanocarrier.

\section{Method and Materials}

\section{Nanoemulsion preparation using a modified Phase Inversion Temperature (PIT) Method:}

The components of the nanoemulsion produced [patentpending] were a vegetable oil which, for this application was rice bran oil (RBO) (Tsuno, Japan), the surfactant Solutol HS 15 (BASF, Ludwigshafen, Germany) and deionized water (Millie Q, Bedford, MA). The RBO (0.5g) was added to a $50 \mathrm{~mL}$ autoclaved beaker along with $2.5 \mathrm{~g}$ of the surfactant Solutol, $75 \mathrm{mg}$ Dextran (Mol Wt Mr 1500 from Sigma Cat. 31394, Sigma, Saint Louis, MO) and combined with up to $25 \mathrm{~mL}$ of deionized water with gentle mixing. The PIT (also referred to as HLB (Hydrophile -Lipophile temperature) varies depending upon the HLB number (Hydrophile -Lipophile balance) of the surfactant. PIT rises with increase in HLB number. The mixture was heated and stirred for 5 min@50$60^{\circ} \mathrm{C}$ until the three components form a homogeneous mixture. The distilled water (total volume $=23 \mathrm{~mL}$ ) was added while the mixture was stirring at @ $60^{\circ} \mathrm{C}$ to form an $\mathrm{O} / \mathrm{W}$ emulsion. During heating, when the PIT (or HLB temperature) of the system was reached $\left(65-70^{\circ} \mathrm{C}\right.$, phase inversion zone), the surfactant was in equilibrium with the oil and water phases. Heating and stirring was continued beyond the PIT up to $80^{\circ} \mathrm{C}$ inverting to a $\mathrm{W} / \mathrm{O}$ emulsion. The emulsion was subsequently cooled to room temperature to obtain an $\mathrm{O} / \mathrm{W}$ emulsion.

The particle sizes of the nanoemulsions were determined by dynamic laser light scattering using the Malvern Zetasizer-S (Malvern Instruments Inc., Southborough, MA). The range of particle sizes which can be measured by the Zetasizer is from 0.6 to $6000 \mathrm{~nm}$.

The measurement of zeta $(\xi)$ potential is based on the following principle: the colloidal particles that constitute the nanocarriers dispersed in rice bran oil and Solutol solutions are electrically charged due to their ionic characteristics and dipolar attributes. Each particle dispersed in the solution is measured using the Malvern Zetasizer Nano series Zen 3600 (Malvern Instruments Ltd., Enigma Business Park, Grovewood Road, Malvern, WorcestershireWR14 1XZ, U.K.)

\section{Cell culture and preparation for inoculation}

Chinese hamster ovarian $(\mathrm{CHO})$ cells were maintained in a disposable Petri Dish with $25 \mathrm{~mL}$ (minimum essential medium) MEM culture medium supplemented with glucose $\left(2.0 \mathrm{~g} \mathrm{~L}^{-1}\right)$ and $10 \%$ fetal bovine serum in a $5 \%$ $\mathrm{CO}_{2}: 95 \% \mathrm{O}_{2}$ incubator at $37^{\circ} \mathrm{C}$. The cell passage was carried out at $80-90 \%$ confluency at a $1: 5$ ratio with $0.15 \%$ 
trypsin in $\mathrm{Ca}_{2} \mathrm{Cl}, \mathrm{Mg}_{2} \mathrm{Cl}$-free phosphate-buffered solution (PBS).The cells were counted using a hemacytometer before inoculation.

Two sterilized $250 \mathrm{~mL}$ spinner flasks were prepared for cultivation and each was filled with $100 \mathrm{~mL}$ MEM plus $25 \mathrm{~mL}$ of freshly prepared nanocarriers, or microcarriers $\left(230 \mu \mathrm{M}\right.$ particle size of Cytopore $\left.2^{\circledR}\right)$. Microcarriers were washed with PBS, and a hydration step was performed to remove any air trapped from the microcarrier before being added to the spinner flask. Each flask was placed on a stir plate and inoculated with $2 \mathrm{~mL} \mathrm{CHO}$ cells and maintained in a $5 \% \mathrm{CO}_{2}: 95 \% \mathrm{O}_{2}$ incubator at $37^{\circ} \mathrm{C}$. Stirring was set to minimum speed for agitation. The duration of the growth studies was at least 4-5 days.

Samples were taken from each spinner flask for microscopic examination and growth determination. The cells were counted using a Hemacytometer before inoculation.

Cell density, media lactate, cellular protein and carrier glucose measurements as an indicator of polymer concentration

Numbers of viable cells were obtained with a light microscope using a hemacytometer to determining each culture's cell density.

Media lactate levels were measured by ABCHEM lactate assay kits (Cambridge, MA) to estimate metabolic production of lactate.

For measuring cellular protein concentrations using the Bradford assay [12], $2 \mathrm{~mL}$ of culture media was taken from the spinner flask, centrifuged at $1000 \mathrm{rpm}$ for 10 min, washed 2 times with ice cold phosphate buffered saline [PBS], and centrifuged between washes. Lysis buffer was added to cells; the cell suspension transferred into a centrifuge tube and allowed to incubate for 15 minutes in the cold room to completely lyse the cells. The lysate was centrifuged at $1000 \mathrm{rpm}$ for 15 minutes and the supernatant immediately transferred to a fresh centrifuge tube. The pellet was discarded. The supernatant [cell lysate] was diluted up to $10 \mathrm{x}$ for measurement of the protein concentration.

Glucose concentration as a measure of the glucose content of the polymers dextran and cellulose in the nano and microcarriers, respectively, was determined using the Sigma GAGO-20 glucose kits (Sigma, Saint Louis, MO).

\section{Statistical analysis}

Data were obtained from analyses of triplicate samples and expressed as the mean + standard deviation (SD). One way ANOVA analysis followed by Tukey's " $t$ " test was done on these triplicate groups. A value of $p<0.05$ was considered to be statistically significant.

\section{RESULTS}

Particle size and zeta potential of the nanoemulsions of the dextran-based nanocarrier

As shown in Fig. 1a, particle size Z-average was 25.15 $\mathrm{nm}$ for nanocarriers composed of $75 \mathrm{mg}$ Dextran, $0.5 \mathrm{~g}$
RBO, 2.5g Solutol and $22 \mathrm{~mL}$ water. The polydisperse index (PDI) was 0.312 .

As shown in Fig. 1B, results of Zeta potential for nanocarrier indicated $-3.62 \mathrm{mV}$.

Microcarrier particle sizes and PDI [not shown] were beyond the limits of determination by the Malvern Zetasizer-S.

Cell density, media lactate, nanocarrier glucose and cell protein lysate concentration.

\section{Cell density}

Measurements of viable cell counts [Fig. 2], showed that although viable cell counts on day 5 of culture were higher than baseline (day lof culture) for both the nano and microcarrier-containing $\mathrm{CHO}$ cell cultures, viable cell counts, in CHO cells exposed to nanocarrier [22.3 X10 ${ }^{6}$ $\pm 1.0 / \mathrm{mL}]$ had 10 times higher cell density compared to microcarrier-containing cultures $\left[2.247 \times 10^{6} \pm 0.5 / \mathrm{mL}\right]$ $[\mathrm{p}<0.0035]$.

\section{Media lactate measurements}

On the $3^{\text {rd }}$ day of culture, media lactate levels from $\mathrm{CHO}$ cell cultures exposed to nanocarriers were 1.0927+ $0.033 \mathrm{mg} \mathrm{mL}^{-1}$, which were $12 \%$ higher $[\mathrm{p}<0.0037]$ compared to media from $\mathrm{CHO}$ cells exposed to microcarriers $0.9195+047 \mathrm{mg} \mathrm{mL}^{-1}$.

\section{Cell lysate protein concentrations}

Comparisons between the 2nd and 4th day of culture, showed the protein content of $\mathrm{CHO}$ cells exposed to the microcarriers increased from $24.9+5.4\left(\mathrm{ng} \mathrm{ml}^{-1}\right)$ to $56.8+$ $3.1(\mathrm{ng} / \mathrm{ml})(93 \% ; \mathrm{p}<0.05)$ while CHO cultures exposed to nanocarriers increased from $45.6+4.2\left(\mathrm{ng} \mathrm{ml}^{-1}\right)$ to 111.3 $+6.4\left(\mathrm{ng} \mathrm{ml}^{-1}\right)(144 \% ; \mathrm{p}<0.05)$. In addition, comparisons between the micro and nanocarriers, showed that at 2 nd day of culture protein concentration of lysates from cells exposed to nanocarriers $(45.6+4.2)$ was $83 \%$ greater than microcarriers $(24.9+5.4$-give units; $\mathrm{p}<0.006)$. Similarly, at $4^{\text {th }}$ day of culture, protein concentration of lysates from cells exposed to nanocarriers $(111.3+6.4)$ was $96 \%$ greater than microcarriers $(56.8+3.2)\left(\mathrm{ng} \mathrm{ml}^{-1}\right)$ $(\mathrm{p}<0.0002)$.

\section{Micro and nanocarrier glucose concentrations}

Glucose measurement indicated that dextran-containing nanocarriers had 59\% higher glucose concentration (719 $+139 \mathrm{mg} \mathrm{L}^{-1}$ ) than cellulose-containing microcarrier (411 $\left.+22 \mathrm{mg} \mathrm{L}^{-1}\right)[\mathrm{p}<.05]$.

$\mathrm{CHO}$ cell cultures exposed to nanoemulsions without added dextran, didn't promote any additional cell growth (data not shown).

\section{DISCUSSION}

Cell density in a bioreactor is correlated with biologics production such as proteins but not limited to lysosomal enzyme production [13]. Microcarriers have been used to promote cell density-associated increase in 
Resills

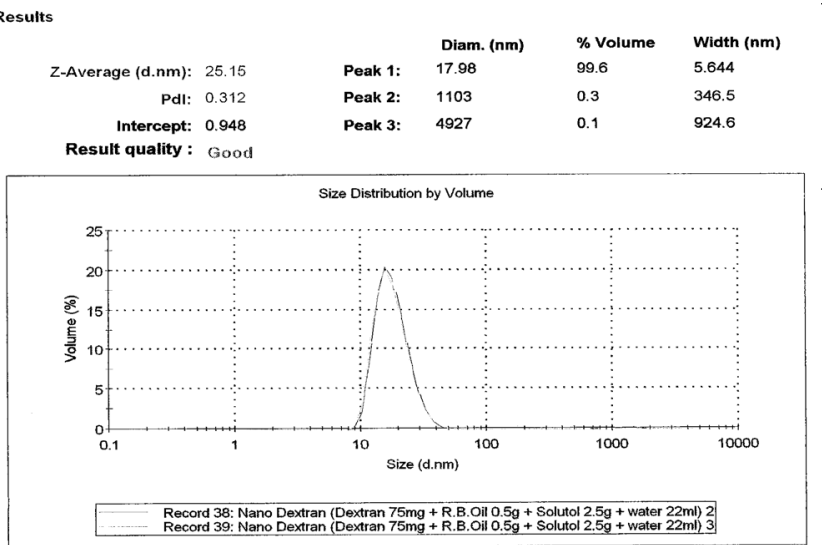

\begin{tabular}{|c|c|c|c|c|}
\hline & & Mean $(m V)$ & Area $(\%)$ & Width (mV) \\
\hline Zeta Potential (mV): -3.62 & Peak 1: & -3.62 & 100.0 & 3.43 \\
\hline Zeta Deviation (mV): 3.43 & Peak 2: & 0.00 & 0.0 & 0.00 \\
\hline Conductivity (mS $\mathbf{c m}$ ): 0.160 & Peak 3: & 0.00 & 0.0 & 0.00 \\
\hline
\end{tabular}
Peak 3: 0.000

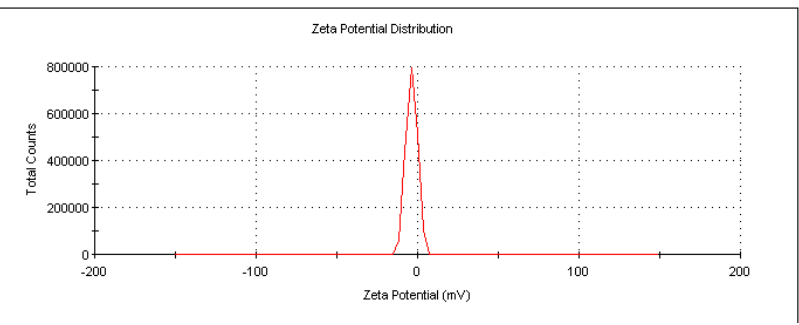

Fig. 1(a) Particle size analysis of nanocarriers showing the Z-average Fig. 1(b) Particle size analysis of nanocarriers showing the zeta size distribution of the particle. As shown, nanoemulsion technique can potential of nanospheres. As shown, particles have a mean of $-3.62 \mathrm{mV}$ be used to formulate in the range of $25-30 \mathrm{~nm}$ and the PDI was 0.192 . zeta potential.

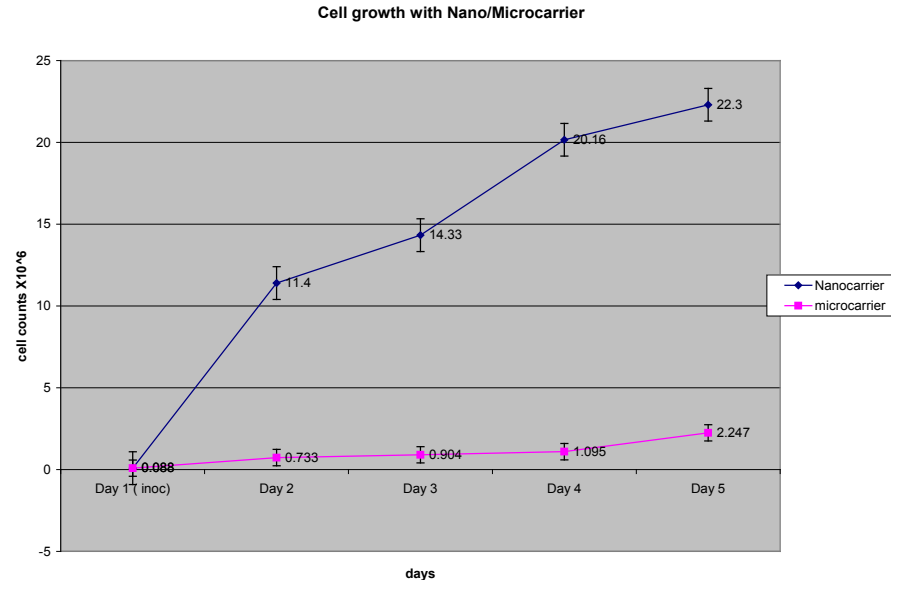

Fig. 2 Differences in viable cell densities between nanocarriers and microcarrier-containing cell cultures maintained for up to 5 days. Values represent the Mean + SEM for three experiments. At every time point measured, the culture with nanocarriers had 10 times higher cell densities than the cell cultures exposed to microcarriers $(p<0.006)$.

biologics production [2]. As dextran was incorporated into microcarriers in early days [9] before switching to cellulose, dextran-derived nanocarriers were used in the SANE-based nanocarriers for comparative purposes.

Microcarriers have the advantage of [a] increasing production capacity [b] enhancing separation of cells from secreted end products $[\mathrm{c}]$ protecting against physical stress [d] reducing the required volume of cell culture media [e] reducing labor intensity and [f] lowering risk of contamination [2]. In earlier studies, use of dextran microcarriers led to enhanced cell attachment with anchorage cells, and to increased cell density [9]. Since then, a variety of microcarriers have been developed for optimization of cell culture-mediated production of biologics which has subsequently improved the quality of the microcarrier [14]. However, more modifications of the microcarriers were developed to enhance cell growth such as increasing the porosity of polymers for greater cell attachment and growth, addition of cellulose and gelatin [15], collagen [16], glass, and polyethylene [17] materials. This increase in porosity provides extended surface area in the interior and additional attachment

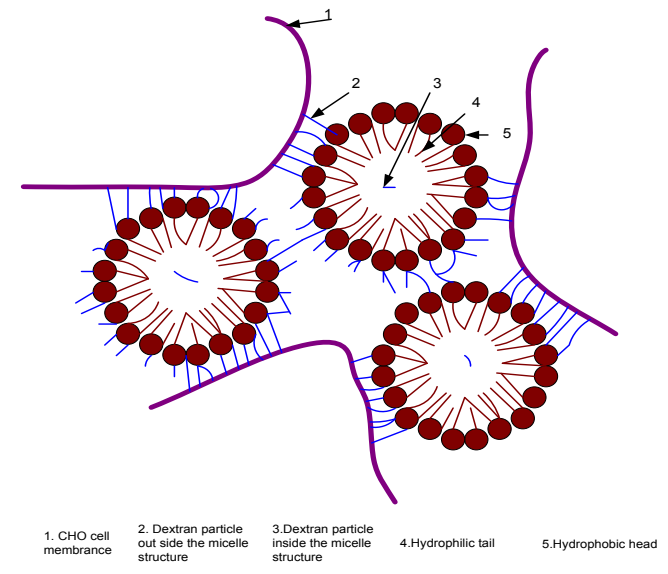

Illustration 1: Dextran paticles are located in and out side of Micelle Structure from SANE. Outside Hydrophilic detran paticles are attached to $\mathrm{CHO}$ cell membrane

space [18] which can support higher cell concentration with an equivalent number of beads. For example, our comparative porous microcarriers which were made from cellulose [11] have an average pore diameter of approximately $30 \mu \mathrm{M}$ [19]. These pore sizes allow 14-15 $\mu \mathrm{M}$ range $\mathrm{CHO}$ cells to enter into this porous microcarrier [18].

Dextran-derived materials have been widely used in biologic application because they [a] provide a matrix for anchorage-dependent cells to attach to [b] have a simple glucose backbone raising the possibility that functional groups can be attached for targeting purposes [c] have a neutral $\mathrm{pH}[\mathrm{d}]$ are water soluble [e] are biodegradable, [f] demonstrate ease of removal by simple filtration and [g] are biocompatible [10]. Thus, dextran was also included in our nanocarrier system instead of using cellulose based nanocarriers. Although both the polysaccharides, cellulose and dextran, are biosynthesized, and are made of glucose, their physical and chemical properties are different, such as, their repeating glucose units being linked together by ( $\beta$ $1 \rightarrow 4)$ for cellulose and $(\alpha 1 \rightarrow 6)$ linkages for dextran. In addition, cellulose has two hydroxyl groups $(\mathrm{OH})$ and one 
hydroxymethyl group $\left(\mathrm{CH}_{2} \mathrm{OH}\right)$ per glucose ring, whereas dextran has three $\mathrm{OH}$ groups and no $\mathrm{CH}_{2} \mathrm{OH}$ group [20]. The molecular mobility in amorphous materials such as dextran and cellulose is generally attributed to localized, thermally activated motions, and it leads to macroscopic mechanical or dielectric behavior [21]. In addition to these differences, dextran was selected for attaching the cell membranes instead of cellulose, since the latter also contained pores suggesting potentially different mechanism(s) of action regarding their ability to increase cell density.

\section{Entrapment versus attachment}

Despite having similar concentrations of polymer (75 mg) dextran for nanocarriers and $75 \mathrm{mg}$ for porous cellulose-based microcarriers, our nanocarrier system has a greater surface to volume ratio by virtue of their nanoparticles having a particle size of $26 \mathrm{~nm}$ compared to 30 micron pores contained in the cellulose-based microcarriers [18]. This means the dextran-nanocarriers have almost 1000 times higher numbers of particle than 30 micron pore size microcarriers. The finding that the dextran-containing nanocarriers had 59\% higher glucose concentration than cellulose-containing microcarrier supports our hypothesis that the dextran-containing nanocarrier had higher dextran particles than cellulosecontained microcarrier. Thus the increased dextran molecules in our nanocarriers result in higher number of cell attachment than is possible for the cellulose containing microcarrier (Illustration 1).

In our nanocarrier system, cells can be attached to these nanocarriers instead of being trapped within the porous microcarrier. Previous reports indicate that use of microcarriers increased cell density due to greater surface to volume ratio [22]. In this communication, the greater surface-to volume ratio coupled with increased content of the polymer dextran of the nanocarriers presumably would support the attachment of more anchorage dependent cells in a given volume (up to 10 fold). This is consistent with the reported findings, that a scaffold composed of ultrafine nanofibers provides the added benefit of improved mechanical properties and more extensive substrate for cell attachment [28]. In addition, dextran containing particles are reported to have higher loading capacity and loading efficiency [29]. Therefore, having outside of the micelle structure, as shown in Illustration 1, dextran particles can be attached strongly with the cell membrane.

Higher cell density has been reported to be associated with higher productivity [24, 25, 27]. Although we did not measure any direct relationship between cell density and productivity, our finding at days 2 nd and $4^{\text {th }}$ that cell cultures which were exposed to nanocarriers had significantly higher cellular protein concentration, presumably as an indicator of the production of a proteinbased biologic than our controlled microcarriers would support that notion.

In biomanufacturing processes, lactate measurement is one of the metabolites monitored as an indicator of increasing $\mathrm{CHO}$ cell densities $[23,26]$.

Our lactate findings results indicate that media from cells exposed to our dextran nanocarriers had higher lactate concentration than microcarrier-containing cultures supporting the proposed association between increasing cell density and higher rates of metabolism

Our findings in this communication are supported by the study of Ryu (30) who showed the poly (lactic-coglycolic acid) (PLGA) nanospheres (696 nm in average diameter) promoted the enhancement of growth for anchorage-dependent animal cells to suspension culture. Their method may be useful for the mass production of recombinant proteins through large-scale suspension culture of anchorage-dependent animal cells. However, their poly (lactic-co-glycolic acid) (PLGA) nanospheres were $696 \mathrm{~nm}$ in average diameter compared to the mean particle size of 20-30 $\mathrm{nm}$ for our nanocarriers.

Important issues such as nanocarrier stability over the usual duration of a perfusion bioreactor producedbiologics for 30 days or more (Only 7 day duration studies were reported in this communication) could not be performed due to limitations in bioreactor availability and optimum conditions for conduction of the studies.

In summary, our studies have shown that dextrancontaining nanocarriers promote cell density greater than a microcarrier system. These findings are supported by (a) increased concentration of polymer of the nano vs. microcarrier (b) numbers of viable cells, (c) cell lysate protein and media accumulation of lactate of $\mathrm{CHO}$ cell cultures exposed to nanocarriers vs. microcarriers.

\section{Acknowledgements}

$\mathrm{T}$

\section{References}

1. Lars Keld Nielsen, Bioreactors for Hematopoietic Cell Culture. Annual Review of Biomedical Engineering. 1999; 1:129-152 http:// dx.doi.org/10.1146/annurev.bioeng.1.1.129

2. Microcarrier cell culture, Principles and methods, Hand book, GE health care. Ney Jersey: Amersham Biosciences Corp, 2005

3. Kathy Wong, Madhusudan Peshwa, Wei Hu, Overview of Microcarrier culture. Cellular Bioprocess Technology 1-8, 2004

4. Kwon YJ, Peng CA. Calcium-alginate gel bead cross-linked with gelatin as microcarrier for anchorage-dependent cell culture. Biotechniques. 2002; 33:212.

5. Croughan MS, Hamel JF, Wang DIC. Hydrodynamic effects on animal cells grown in microcarrier culture. Biotechnology Bioeng 29:130-41, 1987.http://dx.doi.org/10.1002/bit.260290117

6. Sinacore MS, Drapeau D, Adamson SR. Adaptation of mammalian cells to growth in serum-free media. Mol Biotechnology. 2000; 15:249-57, http://dx.doi.org/10.1385/MB:15:3:249

7. Deyu Kong, Reiner Gentz \& Junli Zhang, Development of a versatile computer integrated control system for bioprocess controls. Cytotechnology 1998; 26:3.

8. Protein purification, Amersham Pharmacia Biotech, Uppsala, Sweden, 2001: www.genomics.bham.ac.uk/Documents/ ProteinPurification.pdf

9. Levine DW, Wang DIC. and Thilly WG. Optimization of growth surface parameters in microcarrier cell culture. Biotechnology. Bioeng 1979; 21:821-845.http://dx.doi.org/10.1002/bit.260210507

10. Properties of dextran, Dextran chemistry, manufacturers of dextran 
Pharmacosmos. Holbaek, Denmark

11. Han et al. Cultivation of Recombinant Chinese Hamster Ovary Cells Grown as Suspended Aggregates in Stirred Vessels. J Biosci Bioeng. 2006; 102, 5:430-5.http://dx.doi.org/10.1263/jbb.102.430

12. Marion M. Bradford, rapid and sensitive method for the quantization of microgram quantities of protein utilizing the principle of proteindye binding Analytical Biochemistry 1976; 72:1-2: 248-254.

13. Thomas Kiy, Gerda Scheidgen-Kleyboldt, Arno Tiedtke, Production of lysosomal enzymes by continuous high-cell-density fermentation of the ciliated protozoon Tetrahymena thermophila in a perfused bioreactor. Enzyme and Microbial Technology. 1996; 18:4:268-274, March .http://dx.doi.org/10.1016/0141-0229(95)00076-3

14. CAM Velden-de Groot, Microcarrier technology present status and perspective, Cytotechnology.1995; 18:4: 51-56, http://dx.doi. org/10.1007/BF00744319

15.Nilsson K, Buzsaky F, \& Mosbach K. Growth of AnchorageDependent Cells on Macroporous Microcarriers. Bio/Technology 1986; 4:989-990. http://dx.doi.org/10.1038/nbt1186-989

16. Dean RC, Jr, Karkare, SB, Phillips PG, Ray NG, and Runstadler PW Jr. Continuous cell culture with fluidized sponge beds. In Lyderson, B. K. (ed.), Large scale mammalian cell culture technology. Hanser Publications, New York, NY, 1987; 145-167

17.Preissmann A, Wiesmann R, Buchholz RG, Werner R, Noé W, Investigations on oxygen limitations of adherent cells growing on macroporous microcarriers. Cytotechnology. 1997; 24, 2: 121-134. http://dx.doi.org/10.1023/A:1007973924865

18. Ng Y-C, Berrym JM, Butler M. Optimization of physical parameters for cell attachment and growth on macroporous microcarriers. Biotechnology and Bioengineering. 1996; 50: 6:627-635.

19.L Ikonomou, J Drugmand, G Bastin, Y Schneider, S Agathos, Microcarrier Culture of Lepidopteran Cell Lines: Implications for Growth and Recombinant Protein Production, Biotechnology Progress. 2002; 18, 6:1345-1355. http://dx.doi.org/10.1021/ bp0255107

20.D. Kong, M. Chen, R. Gentz,J. Zhang, Cell growth and protein formation on various microcarriers, Cytotechnology. 1999; 29, 2:151158.http://dx.doi.org/10.1023/A:1008053421462

21. De La Rosa A, Heux L, Cavaille JY. Secondary relaxations in poly (allyl-alcohol), PAA, and poly (vinyl alcohol), PVA: Part I. mechanical relaxations compared with mechanical behavior of cellulose and dextran in the presence of polar solvent Polymer 2000; 41, 20:7547-7557.http://dx.doi.org/10.1016/S0032-3861(00)00061-6

22. Montagnon BJ. Polio and rabies vaccines produced in continuous cell lines: a reality Vero cell line. Dev. Biol. Stand 1989; 70: 27-42,

23. Zhang, Yuan-Xing, Sun, Xiang-Ming, Estimation of Chinese hamster ovary cell density in packed-bed bioreactor by lactate production rate. Biotechnology Letters. 2003; 24, 11:853-857.

24.Wurm FM Production of recombinant protein therapeutics in cultivated mammalian cells. Nat Biotechnology 2004; 22:1393-1398 http://dx.doi.org/10.1038/nbt1026

25. J Yang, A Angelillo, M Chaudhry, C Goldenberg. Achievement of high cell density and high antibody productivity by a controlledfed perfusion bioreactor process, Biotechnology and Bioengineering 69,1:74-82, 2000http://dx.doi.org/10.1002/(SICI)10970290(20000705)69:1<74::AID-BIT9>3.0.CO;2-K

26.Tsao Y, Cardoso AG, Condon RGG, et al. Monitoring Chinese hamster ovary cell culture by the analysis of glucose and lactate metabolism, 2005

27. A Ayed, I Rabhi, K Dellagi, H Kallel. High level production and purification of human interferon [alpha] $2 \mathrm{~b}$ in high cell density culture of Pichia pastoris, Enzyme and Microbial Technology 2008; 42,2:173-180,http://dx.doi.org/10.1016/j.enzmictec.2007.09.006

28. WJ Li, RTuli, X Huang, P Laquerriere and RS Tuan, Multilineage differentiation of human mesenchymal stem cells in a threedimensional nanofibrous scaffold, Biomaterials. 2005; 26:51585166, http://dx.doi.org/10.1016/j.biomaterials.2005.01.002

29. Liu Z, Cheung R, Wu XY, Ballinger JR, Bendayan R, Rauth AM. A study of doxorubicin loading onto and release from sulfopropyl dextran ion-exchange microspheres, J Control Release. 2001; 77, 3: 213-24.http://dx.doi.org/10.1016/S0168-3659(01)00473-4

30.RYU J H, HEK 293 cell suspension culture using fibronectinadsorbed polymer nanocarriers in serum-free medium, Journal of Biomedical Materials Research. 2004; 71A, 1: 128-133.http://dx.doi. org/10.1002/jbm.a.30141

Copyright:(c) 2012 E. Anton, et al. This is an openaccess article distributed under the terms of the Creative Commons Attribution License, which permits unrestricted use, distribution, and reproduction in any medium, provided the original author and source are credited. 